\title{
The use and abuse of the emergency ambulance service: some of the factors affecting the decision whether to call an emergency ambulance
}

\section{G. J. GARDNER}

Accident and Emergency Department, Countess of Chester Hospital, Liverpool Road, Chester, England

\section{SUMMARY}

Over a 1-month period all patients arriving in the accident and emergency department by ambulance following a ' 999 ' call were questioned using a standard proforma. They were assessed as to whether their medical condition warranted ambulance transfer. A number of social and practical points were analyzed to see whether they would identify any group of patients who used the emergency service without medical need. Overall 289 patients were questioned. Of these $178(62 \%)$ were considered to have medically warranted an ambulance call whereas $111(38 \%)$ did not. A number of features which were more likely to result in an unjustified call were identified. These would suggest that basic knowledge of first aid by the public is poor and should be improved.

\section{INTRODUCTION}

One previous paper has investigated the incidence of unnecessary ambulance use in this country (Morris \& Cross, 1978). In that paper a total of $51 \cdot 7 \%$ of calls were deemed unjustified and a further $10 \cdot 2 \%$ were of doubtful necessity. A similar paper from Dublin (which excluded children under the age of 14) has produced results showing a $44 \%$ unjustified rate (O'Leary, et al., 1988). This paper has produced very similar justification rates to Morris \& Cross. Morris \& Cross have concentrated mainly on the analysis of patient by medical specialty and overall outcome. This paper looked at some of these aspects again but also tried to investigate some of the social and practical points

Correspondence: Dr Graham J. Gardner, Senior Registrar in Accident and Emergency Medicine, Manchester Royal Infirmary, Oxford Road, Manchester M13 9WL, England. 
surrounding the ambulance call and hence identify a specific group of the population who misused the system. If such a group could be identified then educational and advertising material to reduce this misuse could be more accurately targetted rathef than aiming at the population as a whole.

\section{METHOD}

Over the course of one month all patients attending the accident and emergencyo department following a '999' call were questioned using a standard proforma (Appendix. 1). Also included were patients who had had an emergency ambulance ordered by their general practitioner after a home visit. Patients accepted by in-patient firms orw transferred direct to the ward were not included. The forms were completed by the doctor attending the patient. In 60 cases this was by myself and in most of the remainder? by the A\&E Senior House Officers (SHOs) although, in the more serious cases, the other registrar or the consultant would have been involved in the patient management. The attending doctor was asked to assess whether, in his or her opinion, a '999' call was justified if the degree of medical urgency was the only criterion. It was not felt possibleto issue comprehensive guidelines as the number of situations to cover would have been too great. However, certain cases were normally accepted as 'justified': any life $\_$ threatening or potentially life-threatening illness (for example, angina); any condition $\vec{\emptyset}$ which was expected to produce severe pain; any condition which produced immobilify or required treatment before transfer; and most road traffic accidents (because of the possibility of spinal injury).

\section{RESULTS}

A total of 289 patients were questioned. Of these $178(62 \%)$ had made justifiable calls whereas $111(38 \%)$ had not. A total of 180 patients had suffered from trauma and $109 \frac{15}{3}$ had a medical illness. Of the 180 trauma patients 91 fell into the justified category and 89 into the unjustified group. Of the 109 patients with medical problems 87 were classified. as justified and only 22 as unjustified.

\section{Age distribution}

Figure 1 shows the age distribution for calls divided into overall, justified and unjustified groupings. Analysis of these groups indicates no significant difference between them (Pearson $\chi^{2}=9.949 \mathrm{df} P=0.3$ ).

\section{Place of incident}

Analysis of these data shows there is no significant difference between the two main ${ }^{\circ}$ groups for any of the different places of incident. (Table $1 . \chi^{2}=10 \cdot 116 \mathrm{df} P>0 \cdot 1$ ). 


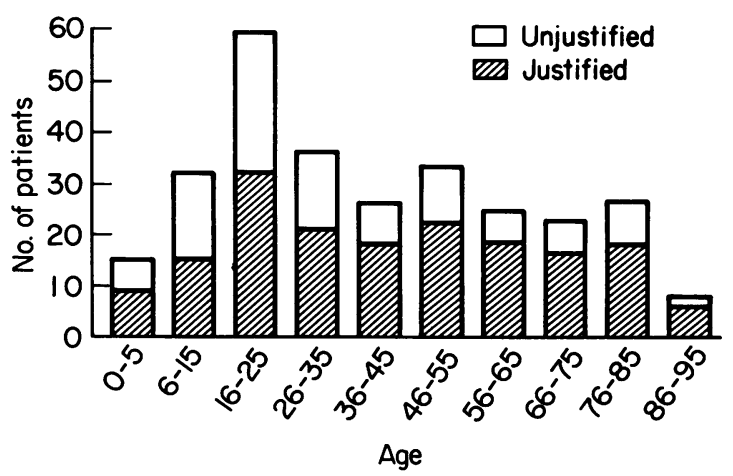

Fig. 1 Age distribution of patients.

Table 1 Place of accident

\begin{tabular}{lcccc}
\hline & \multicolumn{2}{c}{ Justified } & \multicolumn{2}{c}{ Unjustified } \\
\cline { 2 - 5 } & Actual & Expected & Actual & Expected \\
\hline Work & 13 & $10 \cdot 5$ & 4 & $6 \cdot 5$ \\
School & 2 & $4 \cdot 3$ & 5 & $2 \cdot 7$ \\
Home & 69 & $63 \cdot 4$ & 34 & $39 \cdot 6$ \\
Shop & 9 & $7 \cdot 4$ & 3 & $4 \cdot 6$ \\
Street & 51 & $54 \cdot 8$ & 38 & $34 \cdot 2$ \\
Other & 10 & $13 \cdot 6$ & 12 & $8 \cdot 4$ \\
Unknown & 24 & 24 & 15 & 15 \\
\hline
\end{tabular}

Pearson $\chi^{2}=10 \cdot 116 \mathrm{df} P=0 \cdot 12$.

\section{Initiator of call}

There is a significant difference between the two main groups when considering this category (Table $2 \chi^{2}=19.0010 \mathrm{df} P<0.05$ ). Further analysis shows that this is mainly accounted for by the 'relative', and 'other' groups. In the 'relative' group there is a higher number of justified calls than expected. Breakdown of the 'other' group further shows that the main difference is accounted for by friends calling the ambulance. In this case there were more non-justified calls than expected.

Minor contributions to the significance were made by other initiators within this category. When the calls were initiated by the patient, teacher, or passer-by then the call was more likely to be unjustified. When initiated by an employer, shop staff, or GP they were more likely to be justified. 
Table 2 Initiator of emergency call

\begin{tabular}{lcccc}
\hline & \multicolumn{2}{c}{ Justified } & \multicolumn{2}{c}{ Unjustified } \\
\cline { 2 - 6 } & Actual & Expected & Actual & Expected \\
\hline Patient & 7 & $8 \cdot 6$ & 7 & $5 \cdot 4$ \\
Employer & 10 & 8 & 3 & 5 \\
Teacher & 0 & $2 \cdot 5$ & 4 & $1 \cdot 5$ \\
Relative & 45 & 40 & 20 & 25 \\
Shop Staff & 10 & $8 \cdot 6$ & 4 & $5 \cdot 4$ \\
Passer-by & 17 & $19 \cdot 7$ & 15 & $12 \cdot 3$ \\
Works nurse & 3 & $1 \cdot 8$ & 0 & $1 \cdot 2$ \\
GP & 7 & $6 \cdot 2$ & 3 & $3 \cdot 8$ \\
Police/Fire & 5 & $5 \cdot 5$ & 4 & $3 \cdot 5$ \\
Other & 21 & $28 \cdot 3$ & 25 & $17 \cdot 7$ \\
Unknown & 53 & $48 \cdot 7$ & 26 & $30 \cdot 3$ \\
\hline Pearson $\chi^{2}=$ & & & &
\end{tabular}

Pearson $\chi^{2}=19.9010 \mathrm{df} P=0.03$.

\section{Opinion of injury}

There was a significant difference in this category between the two groups (Table $\chi^{2} 3$ df $P<0.05$ ). It can be seen that the category 'life-threatening' contained more

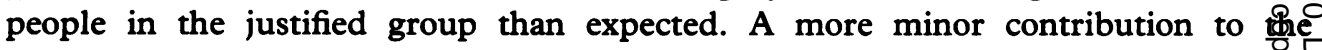
significant difference was made by the fourth category of 'severe pain'. Again more people were in the justified group than expected. Another small contribution to result was made by the 'worried by blood loss' category. This had more unjustified call: confirming the view that patients often estimate blood loss badly.

Table 3 Patients opinion of injury

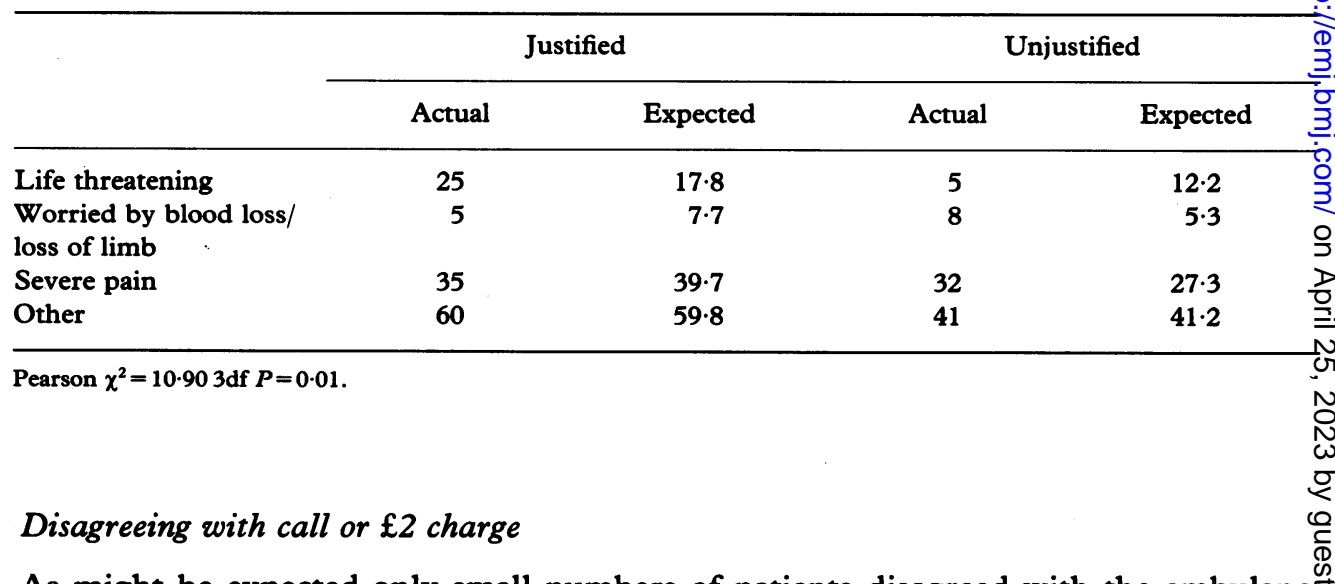

As might be expected only small numbers of patients disagreed with the ambulance being called when it was called by another person (total 21/289). The main people whg did object were epileptics, who would have preferred to have recovered at the scene, an $\phi$ 
a number of drunks. Only 25 would have objected to a $£ 2$ charge being made. Again some of these were epileptics or people from the previous category.

\section{Requiring no treatment}

A total of $64(22 \%)$ patients required no treatment at all following their attendance at A\&E. Nevertheless, 29 of these were considered to have had a condition warranting an ambulance call, for example epilepsy or angina, but had recovered spontaneously. A total of $35(12 \%)$ did not warrant an ambulance for their condition.

\section{Delay between injury and 999 call}

In a number of cases this was unknown and statistical analysis cannot be applied. However, the data available show that most calls in both groups were placed between 0 and 15 minutes following the incident. However, in 25 cases the delay was in excess of $30 \mathrm{~min}(45 \mathrm{~min}-15 \mathrm{~h})$.

\section{Responses to remaining questions}

A number of replies were missing and statistical significance cannot be assigned to these results. However, examination of the data does show some interesting points: Only 35 patients had sought medical advice either from their GP or the A\&E department prior to calling the ambulance; it would seem that having had a similar illness or injury in the past made it more likely that the ambulance call was justified; and having another adult present would also seem to improve the likelihood of a call being justified.

\section{Distance from hospital}

Analysis of the incidence of calls against distance from hospital showed peaks corresponding with the local population centres. It is difficult to decide whether the distance from hospital is a decisive factor as it will be interrelated to a number of other factors such as the GP availability, use of a car, use of a telephone and so on.

\section{DISCUSSION}

In 1978 Morris \& Cross investigated the problem of inappropriate ambulance calls in a major city area. The area under study in this paper is a small city with little urban sprawl and a large surrounding rural area. In addition there are a number of separate large major industrial complexes with their associated residential areas.

Morris \& Cross showed that $61.9 \%$ of these calls were unnecessary or of doubtful validity. This corresponds closely with the findings in this study in which $61.5 \%$ of calls were deemed invalid. However, unlike their study this paper sought to categorize patients purely on medical need without allowing for age or social conditions of the patient. If these other factors had been taken into consideration then it would be expected that the inappropriate call-out rate would have been reduced. 
Table 4 shows how the figures in this paper compare with those by Morris \& CrossT and O'Leary et al. Although O'Leary saw fewer trauma patients the overall justification rates are very similar to this paper. Morris \& Cross saw similar amounts of trauma bu had lower justification rates in both medical and trauma categories. The highex justification rates for medical call-outs shows that an ambulance call to a medicali emergency was much more likely to be justified than that to a trauma case.

The other results show a number of features which relate to the decision to call the ambulance. Some of these improve the quality of the call while a number seem to be related to unwarranted calls:

The peaks of calls in the 15-25 age group is not unexpected and can be explainedo mainly on the basis of assaults and road traffic accidents. O'Leary et al. found that age had an influencing factor on the justification of an ambulance call. They found $86 \%$ of patients over 70 years justified whereas only $47 \%$ of those under 25 were justified. Thisw paper fails to support this finding and there was no difference between the justified ando unjustified calls over the age range. This apparent disparity may be due to the differen?. methods of assessment used in the two papers. In particular, admission was given at heavy weighting in the Dublin paper. Clearly a number of elderly patients will be admitted via A\&E even though they have only minor trauma. 'This is often for 'social'o reasons. These cases for admission are obviously acceptable but they would not beincluded in the justified group for ambulance usage in this paper.

The results suggest that the initiator of call may be important. The reasons for shop staff or employers being more able to determine seriousness than others may be a reluctance to call an ambulance until someone is obviously ill in order to minimige disruption to the workplace or store. Alternatively, it may be because of basic first atdo training which is obligatory in businesses employing over a certain number of peopte leading to better decisions. However, even the Health and Safety Regulations are nota extensive and only require there to be a trained first aider in most businesses employing $\frac{\Omega}{\Omega}$ more than 50 people. That a relative is more able to judge severity than the patient may $\overrightarrow{\vec{O}}$ be because they are able to view things more objectively and, in some cases, may have 3 been nursing the patient for some time, especially if the patient is elderly. Teachers are most likely to order unnecessary ambulances in an attempt to 'cover themselves' and: also may well have no teachers free to bring a child to A\&E. Friends and passers-by are $\stackrel{\mathbb{D}}{3}$ not good judges. This may be for a number of reasons including panicking, not wanting to get involved, and a lack of basic medical knowledge or first aid. Undoubtedly there will be other reasons but the lack of first aid knowledge would seem to be one remedial cause.

Table 4 Comparison of published papers

\begin{tabular}{|c|c|c|c|c|}
\hline & $\begin{array}{c}\text { Trauma/surgical } \\
\% \text { of total }\end{array}$ & $\begin{array}{l}\text { Medical } \\
\% \text { of total }\end{array}$ & $\begin{array}{c}\text { Justified } \\
\text { Trauma \% }\end{array}$ & $\begin{array}{c}\text { Justified } \\
\text { Medical \% }\end{array}$ \\
\hline Gardner & $62 \cdot 3$ & $37 \cdot 7$ & 51 & 80 \\
\hline O'Leary et al. (1987) & $45 \cdot 7$ & $44 \cdot 7$ & 54 & 85 \\
\hline Morris \& Cross (1980) & $57 \cdot 6$ & $36 \cdot 1$ & 37 & 57 \\
\hline
\end{tabular}


It is surprising that the place of the incident seemed to make no significant difference to the validity of the call. It might have been expected that those accidents occurring outside the home or other supportive environment might have resulted in unjustified calls. Analysis of Table 1 shows that more calls than expected were unjustified if the place of accident was school. This would support the previous significant finding that a teacher initiating the call was more likely to be unjustified. Conversely, accidents occurring at work or in a shop resulted in more justified calls than expected which supports the finding that shop staff or employers who initiated the call were more often justified than not.

The results showed that more patients were justified when they felt their condition was 'life-threatening' or where they were in 'severe pain'. Although all the patients in the first group did not, in fact, have life-threatening conditions this choice of category would suggest that these patients had an idea of the seriousness of their complaint. The better results for the second group is somewhat surprising as it often appears that patients with only minor injuries complain of severe pain. However, the figures suggest that pain is an acceptable feature in deciding ambulance useage.

\section{CONCLUSION}

This paper shows that misuse of the ambulance system continues. This is a waste of an increasingly hard-pressed resource. Several methods have been suggested to improve the utilization of this service. In France the Service d'Aide Medicale Urgente (SAMU) employs a doctor (le Regulateur) in the ambulance despatch room to determine which level of response is required, from GP to hospital-based flying squad. In America it has been suggested that a transport ambulance, staffed by emergency medical technicians, is sent to the scene initially thus sparing the more highly trained paramedics (Ehrlich, 1984). However, it is not stated who would make the decision which to send. Both these systems use a service with varying grade of response. The separation of an emergency ambulance service from a routine ambulance service is, in practice, beginning to evolve in this country. Ambulancemen are undertaking extended and advanced training in increasing numbers. It may then be possible to grade response as happens elsewhere. Clearly, for this to happen there will be a need for faster response times to compensate for the delay while an assessment of need is made. Also there would need to be closer links between the ambulance service and the receiving hospital. This has recently been recommended by the Royal College of Surgeons (1988).

Besides changes in the organization of the ambulance service an alteration in the public's management of trauma is necessary. At this time much attention is rightly given to the teaching of bystanders to resuscitate. This is clearly likely to save lives. However, in this paper most of the patients attending $A \& E$ by ambulance were surgical or trauma cases and in these groups there were poor decisions to call an ambulance in $50 \%$ of cases. What is needed is an increased teaching and awareness of the severity and first aid treatment of minor trauma. A number of voluntary organizations already run first aid courses and should be encouraged. Within schools there is an increasing willingness to include subjects of relevance to everyday life and a recognized first aid 
course should be included so that all school-leavers have some basic skills. Unfortum nately, the Department of Education and Science issues no guidelines or recommenda角 tions suggesting this at present but should be persuaded to do so in the future. These simple measures would help to avoid panic and allow a more reasoned approach to thథ injured person.

\section{ACKNOWLEDGEMENTS}

I would like to thank all the staff of the A\&E Department Countess of Chester Hospital for their help in collecting this data. Also thanks to Miss A. Harding, District Planning Officer, for invaluable help in the statistical analysis of the results.

\section{REFERENCES}

Ehrlich B. A. (1984) Inappropriate use of ambulances. New England fournal of Medicine 12, 801.

Morris D. L. \& Cross A. B. (1980) Is the emergency ambulance service abused? British Medical fournal 3\% 121-3.

O'Leary C., Bury G., McCabe M., Kelly C., McGoldrick F. \& Ward F. (1987) Ambulance-user analysis in anaccident and emergency department. Irish Medical Fournal 80, 422-3.

Royal College of Surgeons of England. Commission on the provision of surgical services. The managemenfor patients with major injuries. (1988).

\section{Appendix 1}

Date:

Time of arrival

Name:

Address:

Date of birth:

Place of accident (address)

Was this: Work School Home Shop Street Other

Was ambulance called by Patient Employer Teacher Relative Shop staff Passeg

by Works nurse GP Other

Was another responsible adult present at the scene $(y / n)$

Did patient have access to a car $(\mathbf{y} / \mathbf{n})$

Did patient have access to public transport $(\mathbf{y} / \mathbf{n})$

Did patient have access to a private telephone $(\mathbf{y} / \mathbf{n})$

Had the patient contacted the GP before making call $(y / n)$

Had patient contacted A \& E before making call $(y / n)$

Had the patient had a similar emergency before-specify

What was the time of the accident

What was the delay between accident and 999 call

Patients opinion of injury: Life threatening Dangerous because of blood loss

extremity Severe pain Other (specify)

If ambulance called by someone other than patient does the patient agree to the call $(y / n)$

If a charge of $£ 2$ was made for ambulance would the call still have been made ( $y / n)$ 
Medical details:

Investigations:

Final diagnosis:

\section{Treatment:}

Admitted $(\mathbf{y} / \mathbf{n})$ If Yes Ward No =

Based on medical urgency only, in your opinion, was a 999 call justified ( $y / n)$ 